\title{
Evidence-Based Therapy May Improve Outcome in Glomerulonephritis-A Prospective Field Survey
}

\author{
Norbert Braun ${ }^{1}$, Anna Schweisfurth ${ }^{2}$, Hermann-Josef Gröne ${ }^{3}$, Guenther Kundt ${ }^{4}$ \\ ${ }^{1}$ Department of Internal Medicine, MediClin Müritz-Klinikum, Waren, Germany \\ ${ }^{2}$ Department of Nephrology and Dialysis, HELIOS Hospital, Schwerin, Germany \\ ${ }^{3}$ Department of Cellular and Molecular Pathology, German Cancer Research Centre, Heidelberg, Germany \\ ${ }^{4}$ Institute for Biostatistics and Informatics in Medicine, University of Rostock, Rostock, Germany \\ Email: norbert.richard.braun@t-online.de
}

Received July 4, 2012; revised August 10, 2012; accepted August 20, 2012

\begin{abstract}
Introduction and Aims: Although glomerulonephritis is rare in the general population it is the second most important cause for end-stage renal failure. The therapy of glomerulonephritis is guided by a limited number of individual clinical trials and treatment recommendations are based on meta-analysis and Cochrane Systematic Reviews. The impact of such therapy standards on the prognosis of glomerulonephritis is not known. Methods: Between October 2002 and December 2008 patients with abnormal urine findings and/or decreasing renal function of unknown cause were referred for renal biopsy. In a collaboration of out-patient nephrologists with a major teaching hospital, all patients received treatment recommendations according to evidence-based therapy guidelines based on Cochrane Systematic Reviews. Patient charts were systematically reviewed and patients were re-examined for follow-up until November 2009. Cox Regression analysis was performed to identify independent prognostic factors. Results: Two hundred patients with primary or secondary glomerulonephritis were identified. Complete follow-up data were available from 196 patients with 324 therapeutic interventions. The mean follow-up was $2.8 \pm 2.0$ years. Among all patients, $37 \%$ remained unchanged ill, $13 \%$ died, $17 \%$ had progressing renal disease, while $19 \%$ had a complete and $14 \%$ a partial remission. Proteinuria declined in primary glomerulonephritis $(5.0 \pm 5.4 \mathrm{~g} / \mathrm{d}$ to $2.1 \pm 3.4 \mathrm{~g} / \mathrm{d}, \mathrm{p}<0.001)$ and secondary glomerulonephritis $(4.8 \pm$ $4.6 \mathrm{~g} / \mathrm{d}$ to $2.7 \pm 3.1 \mathrm{~g} / \mathrm{d}, \mathrm{p}=0.004)$. The highest rates of remission were observed in minimal change disease $(83 \%)$ and membranous nephropathy (50\%). Survival was lowest in MPGN and secondary rapid-progressive glomerulonephritis (33\% and 50\%, respectively). 70 (22\%) interventions were complicated by adverse events resulting in treatment cessation in 25 cases. Cox univariate analyses identified the following parameters to improve outcome: Histology, no tubulointerstitial fibrosis, primary glomerulopathy, absence of hypertension at presentation, diabetes, ischemic heart disease, no diuretics or insulin, serum creatinine $<175 \mu \mathrm{mol} / 1$, blood pressure $<160 \mathrm{mmHg}$, age $<60$ ys, prednisolone, cyclosporin A, azathioprine, and follow-up by $24 \mathrm{hr}$ urine. In a multivariate forward Cox regression analysis, tubulo-interstitial fibrosis had a hazard for the combined end-point of death, dialysis and progression of renal failure of $4.4(95 \%$ confidence interval (95\% CI: 1.8 - 10.6) while intensive follow-up by regular $24 \mathrm{hr}$ urine collections reduced the risk to 0.3 (95\% CI: $0.1-0.7)$, treatment with prednisolone had a hazard of 0.3 (95\% CI: $0.1-0.9)$, and cyclosporin A therapy a hazard of 0.2 (95\% CI: $0.02-1.4)$. Application of Cochrane review based therapy guidelines along with intensified monitoring of renal function prolonged dialysis-free survival by 1.7 years. Conclusions: In a multivariate model of standardised glomerulonephritis therapy the presence of tubulointerstitial fibrosis was associated with death or progresssive renal disease, while prednisolone-based therapy regimens and intensified nephrological follow-up resulted in a significant delay of endstage-renal failure. This result should direct future health care policies because glomerulonephritis accounts for nearly $20 \%$ of the dialysis population.
\end{abstract}

Keywords: Glomerulonephritis; Therapy; Evidence-Based Medicine; Treatment Recommendation; Field Survey; Immunosuppression; Tubulointerstitial Fibrosis; Cox Regression Analysis

\section{Introduction}

Glomerulonephritis can be classified as a rare disease because the prevalence is less than 5 per 10,000 population [1]. Rare diseases are a threat to the health of EU citizens insofar as they are life-threatening or chronically debilitating diseases with a low prevalence and a high level of complexity [2]. Thus, glomerulonephritis is the underlying disease for $19 \%$ of all dialysis-dependent patients in Germany [3]. Similar numbers are reported from the United Kingdom [4] and the United States of Amer- 
ica [5] making glomerulonephritis to the second most important cause for end-stage renal disease beside diabetes mellitus. Systematic diagnosis and therapeutic approaches were limited to individual research groups. The results of clinical trials are limited by the small number of included patients. During the last years, systematic Cochrane reviews have tried to summarize the results and give therapeutic recommendations. The validity of such recommendations is still pending and search in Health Technology Assessment databases [6] gives no answer to the question of treatment efficacy or cost absorption by this group of patients.

This paper presents data on the systematic application of recommendations from Cochrane systematic reviews about the therapy of glomerulonephritis in a well-defined population backed by epidemiological data.

\section{Methods}

The study was approved by the Ethical Board of the University of Rostock, ref \# A 2009 33. Written consent was received from all patients.

\subsection{Patients}

Between October 2002 and December 2008 patients with abnormal urine findings and/or decreasing renal function of unknown cause in the state capital of Mecklen-burgLower Pomerania Schwerin and the surrounding counties Nordwestmecklenburg, Güstrow, Parchim, Prignitz, and Ludwigslust were referred for renal biopsy. For details of the patient cohort see Braun et al. [1].

\subsection{Therapy}

Following the establishment of a histopathological diagnosis all patients received treatment recommendations considering their individual clinical presentation. The recommendations were strictly based on evidence-based therapy guidelines as given in continuously updated and published Cochrane Systematic Reviews (cited in their latest version):

Minimal Change Nephropathy (MCN) with nephrotic syndrome: As the Cochrane review by Palmer et al. [7] was inconclusive with respect to the treatment of adults due to a lack of clinical studies, recommendations were deducted from one cited adult study [8] and analogous recommendations given in Cochrane Reviews for the treatment of children [9-11]. Patients received $1 \mathrm{mg} / \mathrm{kgBW} /$ day of oral prednisolone for $4-6$ weeks. In the case of steroid-resistant nephrotic syndrome, cyclosporin A was given in an adult adjusted dose of $3.5-5 \mathrm{mg} / \mathrm{kgBW} /$ day in two divided doses aiming at a full blood through level between $80-140 \mathrm{ng} / \mathrm{ml}$.

Focal and segmental glomerulosclerosis (FSGS): Patients with nephrotic syndrome treated with cyclosporin
A (CSA) at an initial dose of $3.5-5 \mathrm{mg} / \mathrm{kgBW} /$ day in two divided doses in combination with oral prednisolone $0.15 \mathrm{mg} / \mathrm{kgBW} /$ day are more likely to achieve a partial remission of the nephrotic syndrome compared with symptomatic treatment or prednisolone alone [12]. Thus, patients initially received prednisolone $1 \mathrm{mg} / \mathrm{kgBW} /$ day for at least 6 weeks followed by cyclosporin A and prednisolone if still nephrotic. Non nephrotic patients received symptomatic treatment. In the case of cyclosporin resistance a trial with cyclophosphamide was offered [13].

Primary mesangioproliferative glomerulonephritis (MesGN) of the IgA type: Treatment was based on the Cochrane review by Samuels et al. [14] and stratified according to the suggestions by Floege et al. [15] In brief, patients with proteinuria $\geq 1 \mathrm{~g} / \mathrm{d}$ and GFR $\geq 60 \mathrm{ml} / \mathrm{min}$ were treated according to Pozzi et al. [16] but when proteinuria was less than $1 \mathrm{~g} / \mathrm{d}$ only oral prednisolone was prescribed. Patients with deteriorating renal function were treated with oral cyclophosphamide $1.5 \mathrm{mg} / \mathrm{kgBW} /$ day for three months followed by azathioprine and prednisolone $0.5 \mathrm{mg} / \mathrm{kgBW} /$ day [17].

Idiopathic membranous glomerulonephritis (MGN): Treatment was based on the Cochrane review by Schieppati et al. [18]. After stratification according to Cattran [19]. In brief, patients with mild proteinuria $<4 \mathrm{~g} / \mathrm{d}$ and normal renal function were treated symptomatically. Patients with persistent moderate proteinuria $\geq 4 \mathrm{~g} / \mathrm{d}$ and $<8 \mathrm{~g} / \mathrm{d}$ with normal renal function for more than 6 months were treated with a modified Ponticelli scheme using methylprednisolone in combination with $1.5 \mathrm{mg} /$ $\mathrm{kgBW} /$ day cyclophosphamide instead of chlorambucil for 6 months [20]. Patients with persistent proteinuria $\geq 8$ $\mathrm{g} / \mathrm{d}$ and/or deteriorating renal function were treated with an adjusted dose of $3.5-5 \mathrm{mg} / \mathrm{kgBW} /$ day cyclosporin A in two divided doses for at least 6 months. In the case of treatment-resistance an attempt to switch the primary therapy option was undertaken. Patients not responding to this treatment recommendation after one year could be treated experimentally with other immunosuppressants.

Necrotising glomerulonephritis with crescents (NGN): This histological entity presented clinically as rapidly progressive glomerulonephritis and patients were treated as an emergency according to the recommendations of Walters' Cochrane review [21]. Methylprednisolone, oral cyclophosphamide and plasmapheresis were applied for induction therapy and azathioprine was used for maintenance therapy. Antibiotics were not routinely administered to prevent relapse, although in single cases rheumatologists prescribed such medication.

Secondary immune complex nephritis without necrotising glomerulonephritis: These patients who suffered mainly from pauci-immune complex glomerulonephritis 
were treated according to the recommendations of the Cochrane review by Walters et al. [21].

Lupus nephritis: Patients with lupus nephritis class II were treated for non major organ involvement according to the current guidelines of the American College of Rheumatology, i.e. primarily with oral prednisolone 0.5 $\mathrm{mg} / \mathrm{kgBW} /$ day, hydrochloroquine, and if appropriate with azathioprine or cyclosporin A [22]. Patients with class III - IV lupus nephritis were treated according the recommendations of the Cochrane review by Flanc et al. [23] with monthly IV cyclophosphamide and methylprednisolone/prednisolone for six months followed by azathioprine. Patients with class V lupus nephritis were treated with cyclophosphamide only if severe proteinuria $\geq 8 \mathrm{~g} / \mathrm{d}$ and/or deteriorating renal function were present.

Symptomatic treatment: Patients with nephrotic range proteinuria were recommended to take a diet reduced in salt ( $3 \mathrm{~g} / \mathrm{d}$ sodium chloride) and protein $(0.8 \mathrm{~g} / \mathrm{kgBW} / \mathrm{d})$ content. Medication consisted in loop diuretics in combination with ACE inhibitors and angiotensin receptor blockers [24]. For hypertension, additional calcium receptor blockers and $\beta$ receptor blockers were prescribed. Target blood pressure was 125/75 $\mathrm{mmHg}$ but diastolic blood pressure in patients with impaired renal function should be at least below $90 \mathrm{mmHg}$ [25].

\subsection{Definitions}

Patients with nephrotic syndrome were regarded to have complete remission if proteinuria was $\leq 0.3 \mathrm{~g} / \mathrm{d}$ with normal renal function and a serum creatinine $\leq 110 \mu \mathrm{mol} / \mathrm{l}$. Partial remission was defined for all types of glomerulonephritis except MesGN as proteinuria $\leq 2.0 \mathrm{~g} / \mathrm{d}$ (MesGN $\leq 1.0 \mathrm{~g} / \mathrm{d}$ ) and normal renal function. Patients with persistent proteinuria and stable renal function were classified "diseased". Patients with doubling of serum creatinine were considered to have progressive renal disease. A combined end-point of progressive renal failure or death of any cause until last follow-up was defined for statistical analysis.

\subsection{Patient Follow-Up and Patient Adherence}

All patients were offered a personal counselling once the histological diagnosis was established. An interpretation of the histology in association with the clinical presentation and laboratory results were given together with a treatment advice according to the most recent Cochrane Review recommendations. The referring nephrologist then was responsible for the further treatment and data on applied treatment, blood pressure, renal function and proteinuria were monitored prospectively. All patients were advised to collect $24 \mathrm{hrs}$ urine samples in regular intervals for the estimation of endogeneous creatinine clearance and proteinuria by a written instruction sheet.
For most patients and medical practitioners, $24 \mathrm{hrs}$ urine collection is a cumbersome procedure and was not standard before this programme. However, our hypothesis was that regular $24 \mathrm{hrs}$ urine collections demands cooperation of the patient and could increased the patient's insight into the pathomechanism of nephritis and thus, increase the acceptance of correct intake of symptomatic and specific medications.

\subsection{Data Acquisition}

Collection of individual patients' data, biopsy report and treatment recommendation were performed prospectively in a central registry, while treatment and follow-up responsibility was transferred to the referring physician. In the year 2009, records of all patients biopsied between October 2002 and December 2008 were again systematiccally reviewed by a structured form for the following data: Patient identification and pseudonym, age at the time of biopsy, gender, histological diagnosis and percentage of tubulo-interstitial fibrosis in the renal cortex, referring nephrologist or general practitioner, comorbidity (coronary heart disease, peripheral arterial occlusive disease, arterial hypertension, diabetes mellitus), medication with ACE inhibitors, angiotensin receptor blockers, diuretics, HMG CoA inhibitors, insulin, oral antidiabetics, oral anticoagulation or anti-platelet drugs, serum creatinine, MDRD-GFR, endogeneous creatinine clearance, $24 \mathrm{hrs}$ proteinuria or alternatively, spot urinary protein-createnine quotient and dip-stick proteinuria. Blood pressure monitoring was recommended for all patients if possible by ambulatory automatic blood pressure measurement. For statistical analysis mean of systolic and diastolic blood pressure measurements were calculated at the beginning and end of the follow-up. If $24 \mathrm{hrs}$ ambulatory blood pressure recordings were performed, mean of all systolic and diastolic blood pressure measurements were used. Mean arterial blood pressure was calculated according to the formula MAD = diastolic blood pressure + (systolic-diastolic blood pressure)/3.

\subsection{Statistics}

For quantitative parameters we present the results as mean \pm standard deviation (SD) for normally distributed variables or as median and information about the range. Qualitative measurements were given as absolute and relative frequencies. Testing for differences of continuous variables between two independent groups was accomplished by the two-sample t-test or the Mann-Whitney $U$ test by ranks as appropriate. Test selection was based on evaluating the variables for normal distribution employing the Kolmogorov-Smirnov test. Intraindividual changes were tested by using Student's paired t-test. Survival for the combined end-point of progressive renal 
disease or dialysis or death was calculated and graphically displayed according to Kaplan-Meyer method. Differences between curves were assessed by Mantel's logrank test for censored survival data.

The Cox proportional hazards model [26] was used to identify relevant variables influencing the combined endpoint progressive renal failure or dialysis or death. Thereafter, variables yielding $p$-values $\leq 0.20$ in the univariate analyses were entered in the multivariate model to highlight some adjusted associations between the outcome and covariates [27]. All p-values are two-sided, and $p \leq$ 0.05 was considered to be significant. All calculations were performed with PASW Statistics 18 for Microsoft Windows, a courtesy gift by SPSS Munich, Germany (www.spss.com).

\section{Results}

\subsection{Patients and Treatment}

The demographics of the patient cohort is described elsewhere (see "Incidence and prevalence of glomeru- lonephritis in Northern Germany"). In summary, 200 patients (123 males, 77 females, mean age $53 \pm 16$ years) with either primary $(n=130)$ or secondary glomerulonephritis $(\mathrm{n}=70)$ were diagnosed between October 2002 and December 2008. Over this time period, 324 different therapies in 195 patients were analysed. Ninety seven patients $(49 \%)$ received a specific immunosuppressant therapy and 13 patients $(7 \%)$ were not started on their recommended specific treatment. The mean follow-up was $2.8 \pm 2.0$ years (median 2.6 years, range $0.008-7.1$ years). Number of patients in the different glomerulonephritis subtypes, follow-up and their specific first-line therapy recommendations are given in Table 1. Symptomatic treatment was prescribed in 191 patients (96\%), predominantly ACE inhibitors (72\%) and diuretics (71\%). Details are given in Table 2.

\subsection{Outcome}

The highest rate of complete remission was seen in MCN (50\%) followed by MGN (22\%) and MesGN (18\%).

Table 1. Glomerulonephritis subtypes, follow-up and first-line therapy recommendation.

\begin{tabular}{ccccc}
\hline GN Type & N & Follow-up & Therapy according to recommendation & Therapy not begun \\
\hline MCN & 12 & $12(100 \%)$ & 7 P, 1 CsA, 2 S & 2 \\
FSGS & 42 & $42(100 \%)$ & $12 \mathrm{P}, 3 \mathrm{CsA}, 27 \mathrm{~S}^{*}$ & 2 \\
MesGN & 82 & $78(85 \%)$ & $17 \mathrm{MP}, 13 \mathrm{P}, 1 \mathrm{CyP}, 47 \mathrm{~S}$ & 3 \\
MGN & 19 & $18(95 \%)$ & $7 \mathrm{CsA}, 6 \mathrm{CyP}, 2 \mathrm{~S}$ & 1 \\
MPGN & 3 & $3(100 \%)$ & $17 \mathrm{Px} / \mathrm{MP} / \mathrm{CyP}, 1 \mathrm{MP}, 1 \mathrm{P}, 2 \mathrm{~S}$ & 0 \\
NGN & 20 & $20(100 \%)$ & $1 \mathrm{P}, 1 \mathrm{CyP}, 3 \mathrm{MMF}, 1 \mathrm{Aza}, 1 \mathrm{~S}$ & 13 \\
ICN & 7 & $7(100 \%)$ & $1 \mathrm{CyP}, 3 \mathrm{P}, 11 \mathrm{~S}$ & \\
Other & 15 & $15(100 \%)$ & & \\
Total & 200 & $195(98 \%)$ & & \\
\hline
\end{tabular}

$\mathrm{MCN}=$ minimal change nephropathy; FSGS = focal and segmental glomerulosclerosis; MesGN = mesangioproliferative glomerulonephritis; MGN = membranous glomerulonephritis; MPGN = membranoproliferative glomerulonephritis; NGN = necrotising glomerulonephritis; ICN = secondary immune complex nephritis; $\mathrm{P}=$ prednisolone; $\mathrm{CsA}=$ cyclosporin $\mathrm{A} ; \mathrm{S}=$ symptomatic treatment; $\mathrm{MP}=$ methylprednisolone; CyP $=$ cyclophosphamide; $\mathrm{MMF}=$ mycophenolate mofetil; Px = plasmapheresis; Aza = azathioprine, ${ }^{*}$ Patients with secondary FSGS were treated symptomatically only.

Table 2. Supportive therapy according to glomerulonephritis subtype.

\begin{tabular}{cccccccccc}
\hline Diagnosis & N & Supp & ACE-I & ARB & Diuretics & CSE-I & Insulin & Coumarin & Plt-I \\
\hline MCN & 12 & 12 & 10 & 3 & 10 & 7 & 1 & 4 & 0 \\
FSGS & 42 & 42 & 33 & 15 & 34 & 27 & 8 & 5 & 10 \\
MesGN & 82 & 77 & 63 & 30 & 52 & 34 & 12 & 5 & 15 \\
MPGN & 3 & 3 & 3 & 1 & 3 & 3 & 2 & 0 & 1 \\
MGN & 19 & 19 & 17 & 9 & 17 & 14 & 2 & 4 & 4 \\
NGN & 20 & 20 & 8 & 5 & 16 & 8 & 6 & 3 & 2 \\
ICN & 7 & 7 & 3 & 2 & 4 & 3 & 3 & 4 & 1 \\
Others & 15 & 11 & 7 & 3 & 6 & 4 & 4 & 38 & 24 \\
Total & 200 & 191 & 144 & 68 & 142 & 100 & 38 & 36 \\
\hline
\end{tabular}

$\mathrm{N}=$ number of patients; Supp = supportive therapy; ACE-I ACE inhibitors; ARB = angiotensin receptor blockers; CSE-I cholesterin synthesis enzyme inhibitors; Plt-I = platelet inhibitors. 
In all patients, complete remission was achieved in $19.4 \%$. Partial remission was found in one third of the patients with MCN, in $28 \%$ of patients with MGN and in $17 \%$ of patients with FSGS. Complete and partial remission was seen in $33.2 \%$ of all patients. The worst prognosis with respect to progressive renal failure and dialysis was found for FSGS patients (31\%). Patients with NGN and MesGN had progressive renal failure in 20 and $18 \%$, respectively. At the end of follow-up $17.3 \%$ of all patients had either dialysis dependent renal failure or doubling of serum creatinine. Twenty-five patients had died (12.8\%) whereas MPGN and NGN had the worst prognosis. One third of the patients remained unchanged diseased despite specific and symptomatic treatment. Summary of all outcomes is displayed in Table 3.

\subsection{Renal Function and Proteinuria}

Patients with secondary glomerulonephritis had a significantly lower MDRD-GFR $\left(45 \pm 26 \mathrm{ml} / \mathrm{min} / 1.73 \mathrm{~m}^{2}\right)$ compared with patient diagnosed to have primary glomerulonephritis $\left(59 \pm 24 \mathrm{ml} / \mathrm{min} / 1.73 \mathrm{~m}^{2}\right.$, two-sample ttest: $\mathrm{p}<0.001)$. In patients undergoing $24 \mathrm{hrs}$ urine collection endogeneous creatinine clearance did not change over time in the primary glomerulonephritis (initial creatinine clearance $78 \pm 42 \mathrm{ml} / \mathrm{min}$, end of follow-up $84 \pm$ $48 \mathrm{ml} / \mathrm{min}$, paired t-test: $\mathrm{p}=0.14$ ) nor in the secondary glomerulonephritis group of patients $(45 \pm 26 \mathrm{ml} / \mathrm{min}$, $54 \pm 36 \mathrm{ml} / \mathrm{min}, \mathrm{p}=0.76$ ). This was confirmed for the whole cohort by analysis of the changes in MDRD-GFR in primary glomerulonephritis (end of follow-up: $55 \pm$ $28 \mathrm{ml} / \mathrm{min} / 1.73 \mathrm{~m}^{2}$ ) and secondary glomerulonephritis $\left(43 \pm 29 \mathrm{ml} / \mathrm{min} / 1.73 \mathrm{~m}^{2}\right) .24 \mathrm{hrs}$ proteinuria declined significantly in primary $(5.0 \pm 5.4 \mathrm{~g} / \mathrm{d}$ to $2.1 \pm 3.4 \mathrm{~g} / \mathrm{d}$, paired t-test: $\mathrm{p}<0.001)$ and secondary glomerulonephritis $(4.8 \pm 4.6 \mathrm{~g} / \mathrm{d}$ to $2.7 \pm 3.1 \mathrm{~g} / \mathrm{d}$, paired t-test: $\mathrm{p}=$ $0.004)$.

\subsection{Blood Pressure Control}

In primary glomerulonephritis initial systolic, diastolic and mean arterial blood pressure were $134 \pm 16,82 \pm 11$, and $99 \pm 12 \mathrm{mmHg}$ at the time of biopsy and $134 \pm 21$, $78 \pm 12$, and $97 \pm 14 \mathrm{mmHg}$ at the final visit, reaching significance only for the diastolic blood pressure (paired t-test: $p=0.004)$. In secondary glomerulonephritis, systolic, diastolic and mean arterial blood pressures at the time of biopsy were $131 \pm 17,76 \pm 12,94 \pm 14 \mathrm{mmHg}$. At the end of follow-up, no significant differences were observed $(129 \pm 19,75 \pm 10$, and $93 \pm 12 \mathrm{mmHg})$.

\subsection{Adverse Events}

Among the 324 therapeutic interventions which included symptomatic treatment recommendations, 70 (22\%) adverse events were recorded and treatment had to be stopped in 25 cases. Newly diagnosed steroid-induced diabetes in 23 cases and haematological disorders (19 cases) were most frequently reported. Musculoskeletal complaints and Cushing were diagnosed in 13 cases, each.

\subsection{Factors Influencing Outcome}

In Figure 1 we present the result of survival analysis for all 200 patients. The combined end-point of progressive

Table 3. Outcome summery according to glomerulonephritis subtype.

\begin{tabular}{|c|c|c|c|c|c|c|c|}
\hline \multirow{2}{*}{\multicolumn{2}{|c|}{ Diagnosis }} & \multicolumn{5}{|c|}{ Outcome } & \multirow{3}{*}{$\begin{array}{c}\text { Total } \\
12\end{array}$} \\
\hline & & \multirow{2}{*}{$\begin{array}{c}\text { Disease } \\
2\end{array}$} & \multirow{2}{*}{$\begin{array}{c}\text { Death } \\
0\end{array}$} & \multirow{2}{*}{$\begin{array}{c}\text { RF } \\
0\end{array}$} & \multirow{2}{*}{$\begin{array}{c}\text { CR } \\
6\end{array}$} & \multirow{2}{*}{$\begin{array}{c}\mathrm{PR} \\
4\end{array}$} & \\
\hline & $\mathrm{N}$ & & & & & & \\
\hline MICN & $\%$ & $16.7 \%$ & $0 \%$ & $0 \%$ & $50 \%$ & $33.3 \%$ & $100.0 \%$ \\
\hline \multirow{2}{*}{ FSGS } & $\mathrm{N}$ & 16 & 1 & 13 & 5 & 7 & 42 \\
\hline & $\%$ & $38.1 \%$ & $2.4 \%$ & $31.0 \%$ & $11.9 \%$ & $31.7 \%$ & $100.0 \%$ \\
\hline \multirow{2}{*}{ MesGN } & $\mathrm{N}$ & 38 & 3 & 14 & 14 & 9 & 78 \\
\hline & $\%$ & $48.7 \%$ & $3.8 \%$ & $17.9 \%$ & $17.9 \%$ & $11.5 \%$ & $100.0 \%$ \\
\hline \multirow{2}{*}{ MPGN } & $\mathrm{N}$ & 1 & 2 & 0 & 0 & 0 & 3 \\
\hline & $\%$ & $33.3 \%$ & $66.7 \%$ & $0 \%$ & $0 \%$ & $0 \%$ & $100.0 \%$ \\
\hline \multirow{2}{*}{ MGN } & $\mathrm{N}$ & 5 & 3 & 1 & 4 & 5 & 18 \\
\hline & $\%$ & $27.8 \%$ & $16.7 \%$ & $5.6 \%$ & $22.2 \%$ & $27.8 \%$ & $100.0 \%$ \\
\hline \multirow{2}{*}{ NGN } & $\mathrm{N}$ & 4 & 10 & 4 & 2 & 0 & 20 \\
\hline & $\%$ & $20.0 \%$ & $50.0 \%$ & $20.0 \%$ & $10.0 \%$ & $0 \%$ & $100.0 \%$ \\
\hline \multirow{2}{*}{$\mathrm{ICN}$} & $\mathrm{N}$ & 3 & 2 & 0 & 1 & 1 & 7 \\
\hline & $\%$ & $42.9 \%$ & $28.6 \%$ & $0 \%$ & $14.3 \%$ & $14.3 \%$ & $100.0 \%$ \\
\hline \multirow{2}{*}{ Others } & $\mathrm{N}$ & 3 & 4 & 2 & 5 & 1 & 15 \\
\hline & $\%$ & $18.8 \%$ & $25.0 \%$ & $12.5 \%$ & $33.3 \%$ & $6.3 \%$ & $100.0 \%$ \\
\hline \multirow{2}{*}{ Total } & $\mathrm{N}$ & 72 & 25 & 34 & 38 & 27 & 195 \\
\hline & $\%$ & $36.9 \%$ & $12.8 \%$ & $17.4 \%$ & $19.0 \%$ & $13.9 \%$ & $100.0 \%$ \\
\hline
\end{tabular}

$\mathrm{RF}=$ progressive renal failure; $\mathrm{CR}=$ complete remission; $\mathrm{PR}=$ partial remission; for other abbreviations see Table 1. 
renal failure or death was seen in 59 patients until the end of follow-up (Figure 1 (a)). In an univariate Cox regression analysis the following parameters were tested: Gender, age, presence or absence of tubulointerstital fibrosis, primary or secondary glomerulonephritis, initial blood pressure, initial renal function, proteinuria at the time of biopsy, comorbidities, supportive therapy, specific immunomodulatory therapy, and patient adherence to 24 hrs urine analysis. The comparison between the curves of patients with secondary glomerulonephritis and patients diagnosed to have primary glomerulonephritis by using the logrank test results in $\mathrm{p}<0.001$ (hazard ratio (seconddary vs. primary) $2.52,95 \%$ CI: 1.51 to 4.21 ) (Figure 1 (b)).

The risk for progressive renal failure or death was highest in patients with an initial serum creatinine $>175$ $\mu \mathrm{mol} / \mathrm{l}$. For the Kaplan-Meier curves of patients whose biopsy report indicated substantial tubulo-interstitial fibrosis of more than $30 \%$ versus patients with tu-bulointerstitial fibrosis of at most $30 \%$ we received $p<0.001$ (hazard ratio (more than $30 \%$ vs. at most 30\%) 4.71, 95\% CI: 2.03 to 11.0 ) (Figure 1(c)).

Further risk factors were the association with higher age, coronary heart disease or peripheral artery occlusive disease, the development of diabetes mellitus and arterial hypertension. Patients with poor controlled hypertension and systolic blood pressure $>160 \mathrm{mmHg}$ had a significantly higher rate of progression compared to patients with controlled hypertension. Among the tested specific therapy recommendations, prednisolone and cyclosporin A treatment had an advantage over symptomatic and cyclophosphamide treatment (Figure 1(d)). The complete univariate analysis is given in Table 4 .

Independent variables whose hazard ratio test had an error probability of less than 0.2 (see Table 4) were further investigated in a Cox multivariate model with forward regression analysis. After three regression steps no further variables with a $\mathrm{p}$-value $<0.05$ by likelihood ratio testing was found (see Table 5).

The strongest impact on the prognosis of patients with glomerulonephritis was found for the presence of more than $30 \%$ of tubulointerstitial fibrosis in renal cortex as classified by the histopathologist ( $p=0.001$ ). Tubulointersitital fibrosis had a hazard ratio of 4.37 (95\% confidence interval 1.79 - 10.6) for the combined endpoint of progressive renal disease or death. Monitoring the patients renal function with $24 \mathrm{hrs}$ urine sampling decreased the hazard ratio to $0.298(95 \% \mathrm{CI}: 0.139-0.64, \mathrm{p}=$ 0.002; Figure 1(e))

Kaplan-Meier curves of the combined endpoint death, renal failure or progress to renal failure were compared for the group of patients considered compliant with $24 \mathrm{hr}$ urine sampling and the group of patients not being fol lowed up by this method. Mean time to reach the combined endpoint was 5.5 years in the $24 \mathrm{hr}$ urine group and
3.8 years in others. The difference was 1.7 years. Finally, prednisolone or cyclosporin A therapy had a lower hazard ratio in comparision to symptomatic or cyclophosphamide treatment. Overall treatment effect was significant $(\mathrm{p}=0.008)$.

\section{Discussion}

Nowadays, randomised controlled trials are the goldstandard to evaluate a treatment for a specific disease in a well-defined population of patients [28]. However, this approach reaches its limits in so call "orphan" diseases where it is unlikely to design and perform clinical trials with sufficient numbers of patients. Published trials in this area are usually of poor quality, seldom reach significance and do not find the support by the pharmaceutical industry due to the time and money consuming process of performing such a trial. Nevertheless, patients demand treatment and health care officials recognise its importance because of the immense financial burden. In recent years, meta-analysis and Cochrane systematic reviews collecting all available information about the treatment of glomerulonephritis attempted to overcome these problems. However, their results can only be as good as the underlying data which - as stated above-is generally poor. Treatment recommendations derived from such systematic reviews need to be evaluated in daily practice. In this context, glomerulonephritis can be a good example to investigate the role of such gained evidence-based treatment recommendations and its impact on a regional health care policy for various reasons: Firstly, glomerulonephritis is regarded as an orphan disease. Secondly, treatment recommendations on the basis of Cochrane systematic reviews have been published at the beginning of the millennium. Thirdly, glomerulonephritis is a chronically debilitating disease resulting in an extreme cost load for the patient and the health care system all over the world while at the same time physiccians and medical industry earn billions of Euros year by year in keeping those patients with end-stage renal disease at life. The latter may be responsible for the low investment made into clinical research for the prevention of end-stage disease.

In this paper the impact of the implementation of treatment recommendations based on Cochrane systematic reviews for a variety of glomerulonephritis subtypes in a well-defined population of Northern Germany was investigated. Three independent factors influencing the outcome of patients among a multitude of different variables were identified in a Cox mulitvariate model: Tubulointerstitial fibrosis, the application of prednisolone or cyclosporin A, and close follow-up by the responsible physician using $24 \mathrm{hrs}$ urine collection technique. Tubulointerstial fibrosis and immunosuppression are well 




(a)

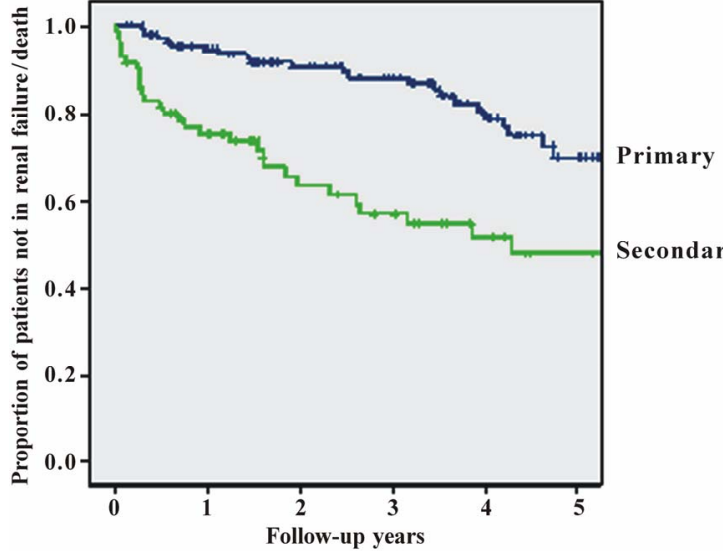

(b)

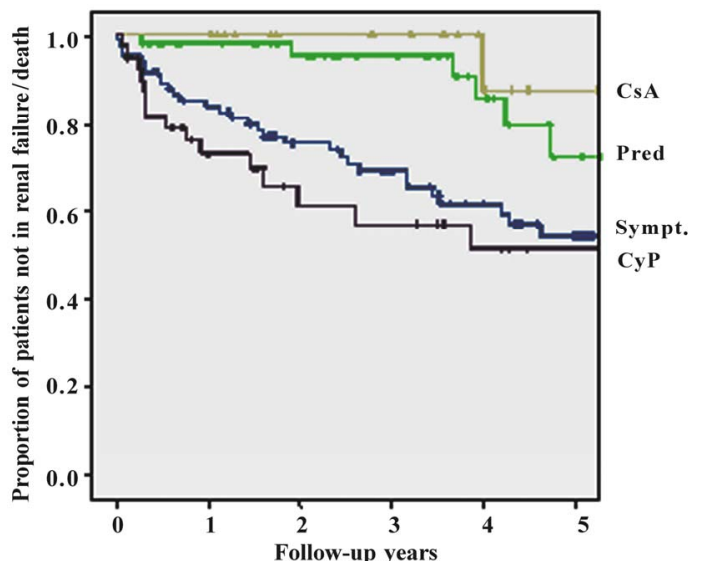

(d)

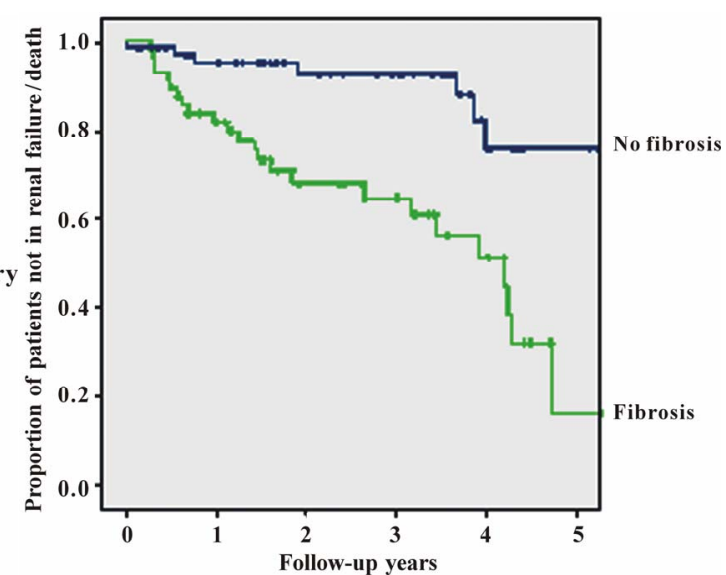

(c)

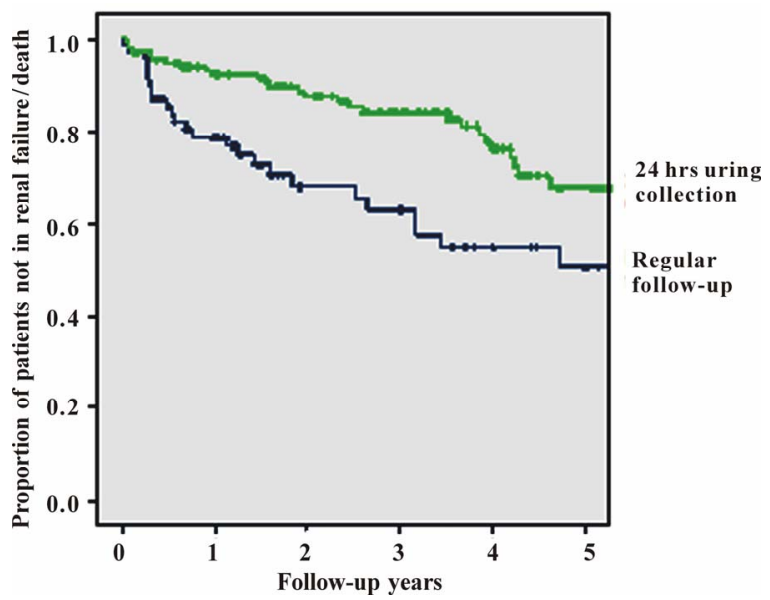

(e)

Figures 1. (a) Cumulative survival of all patients without progressive renal failure; (b) Cumulative survival of patients without progressive renal failure subclassified into primary (upper line) or secondary glomerulonephritis (lower line); (c) Cumulative survival of patients without progressive renal failure subclassified into patients with (lower line) or without (upper line) substantial tubulo-interstital fibrosis of more than $30 \%$; (d) Cumulative survival of patients without progressive renal failure subclassified according to treatment $(\mathrm{CsA}=$ cyclosporin $\mathrm{A}$, Pred $=$ prednisolone only, Sympt. $=$ symptomatic treatment only, CyP = cyclophosphamide based treatment regimen); (e) Cumulative survival of patients without progressive renal failure according to follow-up with or without 24 hrs urine sampling. 
Table 4. Cox univariate model.

\begin{tabular}{|c|c|c|c|}
\hline Variable & p-value & Non adjusted Hazard-Ratio (HR) & 95\%-confidence-interval for $\mathrm{HR}$ \\
\hline $\begin{array}{l}\text { Gender: } \\
\text { male vs. female }\end{array}$ & 0.833 & 0.944 & $0.553-1.612$ \\
\hline Histopathology: & $<0.001$ & & \\
\hline MesGN vs. MCN + FSGS & 0.270 & 0.669 & $0.327-1.368$ \\
\hline MPGN vs. MCN + FSGS ${ }^{*}$ & 0.058 & 4.242 & $0.952-18.904$ \\
\hline MGN vs. $\mathrm{MCN}+\mathrm{FSGS}^{*}$ & 0.504 & 0.674 & $0.212-2.143$ \\
\hline NGN vs. MCN + FSGS ${ }^{*}$ & $<0.001$ & 3.912 & $1.856-8.243$ \\
\hline ICN vs. $\mathrm{MCN}+\mathrm{FSGS}^{*}$ & 0.892 & 1.108 & $0.251-4.884$ \\
\hline Others vs. MCN + FSGS ${ }^{*}$ & 0.988 & 0.993 & $0.378-2.605$ \\
\hline Tubulointerstitial fibrosis: $>30 \%$ vs. $<30 \%{ }^{*}$ & $<0.001$ & 4.712 & $2.026-10.958$ \\
\hline Primary/secondary GN: sec. GN vs. prim. GN ${ }^{*}$ & $<0.001$ & 2.521 & $1.509-4.213$ \\
\hline Hypertension: Arterial hypertension vs. normotension ${ }^{*}$ & 0.018 & 3.416 & $1.233-9.461$ \\
\hline Diabetes mellitus: Diabetes vs. no diabetes ${ }^{*}$ & 0.006 & 2.100 & $1.238-3.564$ \\
\hline Peripheral arterial occlusive disease: PAOD vs. no PAOD ${ }^{*}$ & 0.001 & 4.088 & $1.830-9.133$ \\
\hline Coronary heart disease: $\mathrm{CHD}$ vs. no $\mathrm{CHD}^{*}$ & $<0.001$ & 3.058 & $1.725-5.420$ \\
\hline ACE inhibitors: ACE-I vs. no ACE-I* & 0.129 & 0.658 & $0.384-1.129$ \\
\hline ARB: ARB vs. no ARB ${ }^{*}$ & 0.259 & 0.718 & $0.404-1.277$ \\
\hline Diuretics: Diuretics vs. no diuretics ${ }^{*}$ & 0.003 & 3.267 & $1.481-7.207$ \\
\hline CSE-I: CSE-I vs. no CSE-I* & 0.575 & 0.869 & $0.518-1.441$ \\
\hline Insulin: Insulin vs. no insulin ${ }^{*}$ & 0.001 & 2.537 & $1.461-4.405$ \\
\hline \multicolumn{4}{|l|}{ Coumarine: } \\
\hline Coumarine vs. no coumarine ${ }^{*}$ & 0.327 & 0.652 & $0.277-1.534$ \\
\hline \multicolumn{4}{|l|}{ Platelet aggregation inhibitors } \\
\hline Plt-I vs. no Plt-I* & 0.120 & 1.599 & $0.885-2.886$ \\
\hline \multicolumn{4}{|l|}{$24 \mathrm{hrs}$ urine collection } \\
\hline 24 hrs urine vs. no 24 hrs urine ${ }^{*}$ & 0.002 & 0.432 & $0.256-0.728$ \\
\hline Initial creatinine & $<0.001$ & & \\
\hline $110-175 \mu \mathrm{mol} / 1$ vs. $<110 \mu \mathrm{mol} / 1^{*}$ & 0.165 & 1.945 & $0.760-4.980$ \\
\hline$>175 \mu \mathrm{mol} / 1$ vs. $<110 \mu \mathrm{mol} / 1^{*}$ & $<0.001$ & 12.466 & $5.661-27.450$ \\
\hline Initial proteinuria & 0.258 & & \\
\hline $1-3.5 \mathrm{~g} / 24 \mathrm{hrs}$ vs. $<1 \mathrm{~g} / 24 \mathrm{hrs}^{*}$ & 0.76 & 1.99 & $0.930-4.255$ \\
\hline$>3.5-5 \mathrm{~g} / 24 \mathrm{hrs}$ vs. $<1 \mathrm{~g} / 24 \mathrm{hrs}^{*}$ & 0.675 & 1.26 & $0.427-3.717$ \\
\hline$>5 \mathrm{~g} / 24 \mathrm{hrs}$ vs. $<1 \mathrm{~g} / 24 \mathrm{hrs}^{*}$ & 0.138 & 1.767 & $0.832-3.750$ \\
\hline Initial systolic blood pressure & 0.003 & & \\
\hline $120-140 \mathrm{mmHg}$ vs. $<120 \mathrm{mmHg}^{*}$ & 0.182 & 0.631 & $0.321-1.240$ \\
\hline $140-160 \mathrm{mmHg}$ vs. $<120 \mathrm{mmHg}^{*}$ & 0.953 & 0.978 & $0.460-2.076$ \\
\hline$>160 \mathrm{mmHg}$ vs. $<120 \mathrm{mmHg}^{*}$ & 0.023 & 2.722 & $1.146-6.467$ \\
\hline Initial diastolic blood pressure & 0.098 & & \\
\hline $85-95 \mathrm{mmHg}$ vs. $<85 \mathrm{mmHg}^{*}$ & 0.311 & 0.673 & $0.313-1.448$ \\
\hline$>95 \mathrm{mmHg}$ vs. $85 \mathrm{mmHg}^{*}$ & 0.98 & 1.850 & $0.893-3.833$ \\
\hline Initial mean arterial pressure $>100 \mathrm{mmHg}$ vs. $<100 \mathrm{mmHg}^{*}$ & 0.7 & 1.115 & $0.640-1.941$ \\
\hline Age & $<0.001$ & & \\
\hline $30-60$ y vs. $<30 y^{*}$ & 0.242 & 0.590 & $0.244-1.428$ \\
\hline$>60$ y vs. $>30$ y & 0.042 & 2.364 & $1.032-5.416$ \\
\hline Therapy & 0.004 & & \\
\hline Prednisolone vs. symptomatic treatment ${ }^{*}$ & 0.013 & 0.376 & $0.173-0.817$ \\
\hline Cyclosporin A vs. symptomatic treatment ${ }^{*}$ & 0.030 & 0.206 & $0.049-0.862$ \\
\hline Cyclophosphamide vs. symptomatic treatment ${ }^{*}$ & 0.645 & 1.157 & $0.623-2.147$ \\
\hline
\end{tabular}

$\mathrm{HR}=$ hazard ratio; $\mathrm{MCN}=$ minimal change nephropathy; FSGS = focal and segmental glomerulonephritis; MesGN = mesangioproliferative glomerulonephritis; MPGN = membranoproliferative glomerulonephritis; MGN = membranous glomerulonephritis; NGN = necrotising glomerulonephritis; ICN = secondary immune complex nephritis; PAOD = peripheral artery occlusive disease; $\mathrm{CHD}=$ coronary heart disease; ACE-I $=$ angiotensin receptor inhibitor; $\mathrm{ARB}=$ angiotensin receptor blocker; CSE-I = cholesterin synthesis enzyme inhibitor; Plt-I = platelet aggregation inhibitor; $y=$ years; asterix denotes reference category. 
Table 5. Cox multivariate model with forward regression analysis.

\begin{tabular}{|c|c|c|c|c|}
\hline & & $\mathrm{p}$-value & Adjusted Hazard-Ratio (HR) & 95\%-confidence interval for $\mathrm{HR}$ \\
\hline \multirow[t]{2}{*}{ Step 1} & $24 \mathrm{hrs}$ urine sampling & & & \\
\hline & $24 \mathrm{hrs}$ urine vs. no $24 \mathrm{hrs}$ urine ${ }^{*}$ & 0.002 & 0.298 & $0.139-0.640$ \\
\hline \multirow[t]{4}{*}{ Step 2} & Tubulointerstitial fibrosis & & & \\
\hline & $>30 \%$ vs. $<30 \%{ }^{*}$ & 0.003 & 3.73 & $1.57-8.84$ \\
\hline & $24 \mathrm{hrs}$ urine sampling & & & \\
\hline & $24 \mathrm{hrs}$ urine vs. no $24 \mathrm{hrs}$ urine ${ }^{*}$ & 0.002 & 0.293 & $0.135-0.635$ \\
\hline \multirow[t]{8}{*}{ Step 3} & Tubulointerstitial fibrosis & & & \\
\hline & $>30 \%$ vs. $<30 \%{ }^{*}$ & 0.001 & 4.37 & $1.79-10.6$ \\
\hline & $24 \mathrm{hrs}$ urine sampling & & & \\
\hline & $24 \mathrm{hrs}$ urine vs. no $24 \mathrm{hrs}$ urine ${ }^{*}$ & 0.005 & 0.283 & $0.116-0.687$ \\
\hline & Therapy & 0.008 & & \\
\hline & Prednisolone vs. sympt. ${ }^{*}$ & 0.037 & 0.320 & $0.110-0.934$ \\
\hline & CyA. vs. sympt. ${ }^{*}$ & 0.099 & 0.182 & $0.024-1.38$ \\
\hline & CyP vs. sympt. ${ }^{*}$ & 0.121 & 2.48 & $0.786-7.84$ \\
\hline
\end{tabular}

$\mathrm{HR}=$ hazard ratio; sympt. = symptomatic therapy; $\mathrm{CyA}=$ cyclosporin A therapy; $\mathrm{CyP}=$ cyclophosphamide based therapy; asterix denotes reference category.

known to direct patients into end-stage renal failure [29,30] or induce remission [16,31-34]. The application of cyclophosphamide was not associated with a better survival. This may be due to the negative selection of patients. As shown in the univariate model, secondary glomerulonephritis has a poor outcome. Many of these patients suffered from necrotising glomerulonephritis with severe renal involvement and half of them died or ended on dialysis which is comparable to other recent reports [35]. It was surprising that a simple measure such as 24 hrs urine collection also had a strong impact on the outcome. Previously, it was suggested to replace the $24 \mathrm{hrs}$ urine collection by a spot urine test for proteinuria/urine creatinine ratio [36]. We admit that $24 \mathrm{hrs}$ urine collection may be a process affected by some errors (sampling error, calculation error). Nevertheless, we assume that the process of explaining the collection method and its reason to the patient may contribute to an intensified physician-patient contact and might increase patient and probably physician adherence to recommended therapy strategies by the referral centre. Beside these three main factors, other variables have been shown to improve or worsen outcome. As almost all patients received antihypertensive medication with ACE inhibitors or angiotensin receptor blockers by the end of follow-up, the control of systolic blood pressure is an important determinant for renal progressive disease. On the other hand, the use of diuretics as a poor prognostic factor can be interpreted as a necessary treatment modality for severe nephrotic syndrome which cannot be avoided.

In summary, this paper shows that the application of knowledge derived from Cochrane systematic reviews can be successfully implemented in a region of mainly independently working nephrologists. Treatment recommendations-although widely but not completely followed-showed efficacy in prevention of progression of renal disease. In order to improve patient outcome patients require early renal biopsy, evidence-based treatment recommendation, close renal care including monitoring of their disease status, and strict symptomatic treatment with renin angiotensin blockade aiming at recommended blood pressure targets. If one regards 24 hrs urine collections as an indirect measure of adherence to the recommendations given by the referral centre a prolongation of the time to dialysis can be estimated to approximately 1.7 years. The costs of one year of haemodialysis in Germany are currently 26,200 EUR. Consequently, adherence to treatment recommendations could possibly save 45,000 EUR per treated patient.

\section{Acknowledgements}

We are grateful for the cooperation with the following nephrologists, rheumatologists and general practitioners who submitted data for this analysis:

Dr. Eberhard Schmitt, Dr. Achim Selck, and Jens Freytag, Krückmannstr. 4 - 5, 18273 Güstrow; Dipl.-Med. Cornelia Brenning, Ziegendorfer Chaussee 7, 19370 Parchim; Dr. Kristin Nöhring, Einsteinstr. 12, 17192 Waren; Andreas Morawietz, Reinhard Schodrok, and Dipl.-Med. Maren Paukstat, Kieler Str. 31 a, 19057 Schwerin; Dr. Bernd Gohlke and Dipl.-Med. Niels Baumann, Parkstr. 16, 19230 Hagenow; Michael Pollok and Beate Bley, Bahnhofstr. 29, 19288 Ludwigslust; Dr. Wolfgang Haaf, Kuratorium für Dialyse und Transplantation Wismar, Am Friedenshof, 23966 Wismar; Dr. Margitta Oppermann and Dr. Ilona Lange, K.-Liebknecht-Str. 13a, 19348 Per- 
leberg; Dr. Helge Mentzel and Dr. Astrid Ohlmann, Klützer Str. 6, Grevesmühlen; Frau Inge Selmikat, Dr. Raimar Steinbeck and Dr. Gerd Oehme, Johannes-R.Becher Str. 20, 19059 Schwerin; Dr. Elisabeth Ständer, Beethovenstr. 3, 19053 Schwerin; Dr. Cathleen Bauer and Dipl.-Med. Rainer Kubbutat, Obotritenring 117, 19053 Schwerin; Dr. Roland Schünding, Kieler Str. 31a, 19057 Schwerin; Dirk Gutsmuths, Körnerstr. 22, 19055 Schwerin; Dr. Malte Ganssauge, Alte Dorfstr. 20, 19069 Lübstorf; Dipl.-Med. Jens-Rüdeger Kastorff, Kieber Damm 21, 19300 Grabow; Dr. Rosita Krellenberg, Am Wallhotel 1, 19370 Parchim.

\section{REFERENCES}

[1] N. Braun, A. Schweisfurth, C. Lohofener, et al., "Epidemiology of Glomerulonephritis in Northern Germany," International Urology and Nephrology, Vol. 43, No. 4, 2011, pp. 1117-1126. doi:10.1007/s11255-011-9955-4

[2] Council of the European Union, "Council Recommendation on an Action in the Field of Rare Diseases," Interinstitutional File 2008/0218 (CNS).

[3] U. Frei and H.-J. Schober-Halstenberg, "Nierenersatztherapie in Deutschland 2006/2007," Quasi-Niere gGmbH, Schöneberg, 2008.

[4] K. Farrington, A. Hodsman, A. Casula, D. Ansell and J. Feehally, "UK Renal Registry 11th Annual Report (December 2008): Chapter 4 ESRD Prevalent Rates in 2007 in the UK: National and Centre-Specific Analyses," Nephron Clinical Practice, Vol. 111, Suppl. 1, 2009, pp. c43-c68

[5] S. C. Chen, "United States Renal Data System-The Concise 2008 Annual Data Report," 2008. www.usrds.org.

[6] A. Rüther, H. P. Dauben and H. Schweim, "Die Deutsche Agentur für Health Technology Assessment (HTA) Beim DIMDI (DAHTA@DIMDI),"Bundesgesundheitsbl-Gesundheitsforsch-Gesundheitsschutz, Vol. 44, No. 9, 2001, pp. 865-869.

[7] S. C. Palmer, K. Nand and G. F. Strippoli, "Interventions for Minimal Change Disease in Adults with Nephrotic Syndrome," Cochrane Database of Systematic Reviews, Vol. 23, No. 1, Article No. CD001537.

[8] C.-K. Yeung, K.-L. Wong and W. L. Ng, "Intravenous Methylprednisolone Pulse Therapy in Minimal Change Nephrotic Syndrome," Australian and New Zealand Journal of Medicine, Vol. 13, No. 4, pp. 349-351. doi:10.1111/j.1445-5994.1983.tb04479.x

[9] E. M. Hodson, N. S. Willis and J. C. Craig, "Corticosteroid Therapy for Nephrotic Syndrome in Children," Cochrane Database of Systematic Reviews, No. 4, 2007, Article No. CD001533.

[10] E. M. Hodson, D. Habashy and J. C. Craig, "Interventions for Idiopathic Steroid-Resistant Nephrotic Syndrome in Children," Cochrane Database of Systematic Reviews, Vol. 19, No. 2, 2006, Article No. CD003594.

[11] E. M. Hodson, N. S. Willis and J. C. Craig, "Non-Corticosteroid Treatment for Nephrotic Syndrome In Children," Cochrane Database of Systematic Reviews, No. 4, 2008, Ar- ticle No. CD002290.

[12] N. Braun, F. Schmutzler, C. Lange, et al., "Immunosuppressive Treatment for Focal Segmental Glomerulosclerosis in Adults (Review), Non-Corticosteroid Treatment for Nephrotic Syndrome in Children," Cochrane Database of Systematic Reviews, No. 3, 2008, Article No. CD003233.

[13] G. Banfi, M. Moriggi, E. Sabadini, G. Fellin, G. D’Amico and C. Ponticelli, "The Impact of Prolonged Immunosuppression on the Outcome of Idiopathic Focal-Segmental Glomerulosclerosis with Nephrotic Syndrome in Adults. A Collaborative Retrospective Study," Clinical Nephrology, Vol. 36, No. 2, 1991, pp. 53-59.

[14] J. A. Samuels, G. F. Strippoli, J. C. Craig, F. P. Schena and D. A. Molony, "Immunosuppressive Agents for Treating IgA Nephropathy," Cochrane Database of Systematic Reviews, No. 4, 2003, Article No. CD003965.

[15] J. Floege and H. J. Grone, "IgA-Nephropathie," Der Internist, Vol. 44, No. 9, 2002, pp. 1131-1139. doi:10.1007/s00108-003-1026-1

[16] C. Pozzi, P. G. Bolasco, G. B. Fogazzi, et al., "Corticosteroids in IgA Nephropathy: A Randomised Controlled Trial," Lancet, Vol. 353, No. 9156, 1999, pp. 883-887. doi:10.1016/S0140-6736(98)03563-6

[17] F. W. Ballardie and I. S. D. Roberts, "Controlled Prospective Trial of Prednisolone and Cytotoxis in Progressive IgA Nephropathy," Journal of the American Society of Nephrology, Vol. 13, No. 1, 2002, pp. 42-148.

[18] A. Schieppati, A. Perna, J. Zamora, G. A. Giuliano, N. Braun and G. Remuzzi, "Immunosuppressive Treatment for Idiopathic Membranous Nephropathy in Adults with Nephrotic Syndrome," Cochrane Database of Systematic Reviews, No. 4, 2004, Article No. CD004293.

[19] D. Cattran, "Management of Membranous Nephropathy: When and What for Treatment," Journal of the American Society of Nephrology, Vol. 16, No. 5, 2005, pp. 11881194. doi:10.1681/ASN.2005010028

[20] C. Ponticelli, P. Altieri, F. Scolari, et al., "A Randomized Study Comparing Methylprednisolone Plus Chlorambucil versus Methylprednisolone Plus Cyclophosphamide in Idiopathic Membranous Nephropathy," Journal of the American Society of Nephrology, Vol. 9, No. 3, 1998, pp. 444-450.

[21] G. Walters, N. S. Willis and J. C. Craig, "Interventions for Renal Vasculitis in Adults," Cochrane Database of Systematic Reviews, No. 3, 2008, Article No. CD003232.

[22] American College of Rheumatology Ad Hoc Committee on Systemic Lupus Erythematosus Guidelines, "Guidelines for Referral and Management of Systemic Lupus Erythematosus in Adults," Arthritis \& Rheumatism, Vol. 42, 1999, pp. 1785-1796.

[23] R. S. Flanc, M. A. Roberts, G. F. Strippoli, S. J. Chadban, P. G. Kerr and R. C. Atkins, "Treatment for Lupus Nephritis," Cochrane Database of Systematic Reviews, No. 1, 2004, Article No. CD002922.

[24] C. S. Wilcox, "New Insights into Diuretic Use in Patients with Chronic Renal Disease," Journal of the American Society of Nephrology, Vol. 13, No. 2002, pp. 798-805.

[25] G. Maschio, D. Alberti, F. Locatelli, et al., "Angiotensin- 
Converting Enzyme Inhibitors and Kidney Protection: The AIPRI Trial. The ACE Inhibition in Progressive Renal Insufficiency (AIPRI) Study Group," Journal of Cardiovascular Pharmacology, Vol. 33, Suppl. 1, 1999, pp. S16-S20. doi:10.1097/00005344-199900001-00004

[26] D. Cox, "Regression Models and Life Tables," Journal of the Royal Statistical Society. Series B, Vol. 34, No. 2, 1972, pp. 187-220.

[27] R. Muecke, O. Micke, B. Reichl, et al., "Demographic, Clinical and Treatment Related Predictors for Event-Free Probability Following Low-Dose Radiotherapy for Painful Heel Spurs-A Retrospective Multicenter Study of 502 Patients," Acta Oncologica, Vol. 46, No. 2, 2007, pp. 239-246. doi:10.1080/02841860600731935

[28] D. L. Sackett, S. E. Straus, W. S. Richardson, W. Rosenberg and R. B. Haynes, "Evidence-Based Medicine: How to Practic and Teach EBM," Churchill Livingstone, Edinburgh, 2000.

[29] A. Bohle, S. Mackensen-Haen and G. H. Von, "Significance of Tubulointerstitial Changes in the Renal Cortex for the Excretory Function and Concentration Ability of the Kidney: A Morphometric Contribution," American Journal of Nephrology, Vol. 7, No. 6, 1987, pp. 421-433. doi:10.1159/000167514

[30] D. C. Cattran, R. Coppo, H. T. Cook, et al., "The Oxford Classification of IgA Nephropathy: Rationale, Clinicopathological Correlations, and Classification," Kidney International, Vol. 76, No. 5, 2009, pp. 534-545. doi:10.1038/ki.2009.243

[31] "Safety and Tolerability of Cyclosporin a (Sandimmun) in Idiopathic Nephrotic Syndrome. Collaborative Study
Group of Sandimmun in Nephrotic Syndrome," Clinical Nephrology, Vol. 35, Suppl. 1, 1991, pp. S48-S60

[32] D. C. Cattran, G. B. Appel, L. A. Hebert, et al., "A Randomized Trial of Cyclosporine in Patients with Steroid-Resistant Focal Segmental Glomerulosclerosis. North America Nephrotic Syndrome Study Group," Kidney International, Vol. 56, 1999, pp. 2220-2226. doi:10.1046/j.1523-1755.1999.00778.x

[33] E. Imbasciati, R. Gusmano, A. Edefonti, et al., "Controlled Trial of Methylprednisolone Pulses and Low Dose Oral Prednisone for the Minimal Change Nephrotic Syndrome," British Medical Journal (Clinical Research Edition.), Vol. 291, No. 6505, 1985, pp. 1305-1308. doi:10.1136/bmj.291.6505.1305

[34] D. J. Wallace, D. Goldfinger, G. Savage, et al., "Predictive Value of Clinical, Laboratory, Pathologic, and Treatment Variables in Steroid/Immunosuppressive Resistant Lupus Nephritis," Journal of Clinical Apheresis, Vol. 4, No. 1, 1988, pp. 30-34. doi:10.1002/jca.2920040107

[35] D. R. Jayne, G. Gaskin, N. Rasmussen, et al., "Randomized Trial of Plasma Exchange or High-Dosage Methylprednisolone as Adjunctive Therapy for Severe Renal Vasculitis," Journal of the American Society of Nephrology, Vol. 18, No. 7, 2007, pp. 2180-2188. doi:10.1681/ASN.2007010090

[36] NKF K/DOQI Clinical Practice Guidelines on Hypertension and Antihypertensive Agents in Chronic Kidney Disease," American Journal of Kidney Diseases, Vol. 43, Suppl. 291, 2004, pp. S1-S290. doi:10.1053/S0272-6386(04)00369-5 